Review

\title{
Effectiveness of intervention on behaviour change against use of non-biodegradable plastic bags: a systematic review
}

\author{
Gbadebo Collins Adeyanju, ${ }^{1,2}$ - Teslin Maria Augustine ${ }^{3}$. Stefan Volkmann ${ }^{3}$. Usman Adetunji Oyebamiji ${ }^{3}$. \\ Sonia $\operatorname{Ran}^{3}$. Oluyomi A. Osobajo ${ }^{4}$ (1) Afolabi Otitoju ${ }^{5}$
}

Received: 6 January 2021 / Accepted: 5 February 2021

Published online: 09 March 2021

(c) The Author(s) $2021 \quad$ OPEN

\begin{abstract}
The devastating impacts that bio-degradable products such as plastic bags are having on human health, wildlife, and the environment is enormous, especially single-use once. Single-use plastics are non-biodegradable products and does not undergo biological decomposition nor degenerate. This review examines various government regulations targeted at changing behaviour against plastic bags consumption and their effectiveness. Following a rigorous search in 13 databases, including PubMed, Science Direct, Springer Nature, etc. only 17 peer-reviewed journal articles that are published between 2000 and 2019 and met the inclusion criteria were included in the study. Each study's methodological quality was assessed using the GRADE system, and data were extracted using a uniquely designed form. The results revealed that regulations based solely on the thickness of plastic bags does not reduce plastic bags consumption. However, regulations focused on banning 'single-use' plastic bag usage, imposing higher taxes and levies on consumers, significantly reduce plastic bags consumption. Overall, the latter is considered the most effective. Also, the results show that attitude, perception and behaviour change toward bio-degradable products or climate-friendly behaviour can be significantly influenced by public policy or regulations. Although the behaviour seems short-lived in some countries, therefore further studies need to probe on why. Also, the absence of a national regulatory strategy in North America reduced the inclusion of studies from the region, hence need for more research focusing on sub-national regulations.
\end{abstract}

Keywords Plastic bags - Effectiveness - Intervention - Biodegradable products · Government regulations · Public policy . Behaviour change $\cdot$ Consumption

\section{Background}

We are currently living in the "Plastic Age" [1]. As of 2015, approximately 6300 metric tons of plastic waste have been generated. Out of this, around $9 \%$ was recycled, $12 \%$ was incinerated, and $79 \%$ has accumulated in landfills or the natural environment [2]. Geyer et al. [2] argue that if current production and waste management trends continue, roughly 12,000 metric tons of plastic waste would be in landfills or the natural environment by 2050 . Of plastic types, single-use plastic bags specifically are the most ubiquitous. Often referred to as the world's number one consumer product, single-use plastic, commonly used in business-to-consumer contexts, shopping bags are now among the world's most banned

Gbadebo Collins Adeyanju, gbadebo.adeyanju@uni-erfurt.de | ${ }^{1}$ Centre for Empirical Research in Economics and Behavioural Science (CEREB), University of Erfurt, Erfurt, Germany. ${ }^{2}$ Media and Communication Science, University of Erfurt, Erfurt, Germany. ${ }^{3}$ Willy Brandt School of Public Policy, University of Erfurt, Erfurt, Germany. ${ }^{4}$ Aberdeen Business School, Robert Gordon University, Aberdeen, Scotland, UK. ${ }^{5}$ Africa Partners Initiative E.V. (API), Erfurt, Germany.

Discover Sustainability $\quad$ (2021) $2: 13 \quad$ https://doi.org/10.1007/s43621-021-00015-0 
[3]. In 2015 alone, plastic bag waste accounted for 47\% of the plastic waste generated globally [4]. Most of the world's plastic bag waste comes from Asia, with China being the single largest plastic bag waste generator. On a per-capita basis, the United States of America is the largest generator of plastic packaging waste, followed by Japan and the European Union [4].

There is overwhelming evidence that the abundance of plastic in our ecosystem has a tremendously detrimental impact on the environment, including terrestrial and aquatic ecosystems [5-7]. In this context, countries across the world are trying to regulate plastic use-especially single-use plastics-to reduce plastic consumption and mitigate plastic's detrimental environmental impacts. A comprehensive report published in December 2018 by the United Nations Environment Programme found that globally 127 countries have adopted legislation to regulate single-use plastics [8]. Such regulations range from restrictions on the manufacturing, distribution, use and trade of single-use plastics to financial disincentives, such as taxes and levies. The regulations vary considerably between countries, as does the plastic products' scope and extent covered by such regulations. Certain countries have imposed restrictions on specific products such as plastic plates and cups. Others regulate certain materials such as polystyrene. Still, others regulate the sale and purchase of products containing microbeads [4]. While countries may regulate different products from plastic, the common thread appears to be that they are all single-use plastics. Single-use plastics are categorized as non-biodegradable products because they do not undergo biological decomposition or degenerate over a period. The essential features of singleuse plastics such as adaptability and durable, making it an uncommon target for bacteria also cause it to be classified as non-biodegradable. Hence, single-use plastics linger for decades in the environment, causing a hazard, pollution and unsafe environmental conditions if not properly disposed.

Most of the government initiatives, as shown in Fig. 1 have been prompted by the need for nations around the globe to promote sustainable development by reducing or mitigating against the consumption of plastic bags adverse environmental impacts. The various initiatives in the form of policies and regulations instigated by different governments globally have influenced consumer behaviour concerning plastic bag use in different ways [9]. For example, the Canadian government recently announced plans to "ban harmful single-use plastics as early as 2021 " to reduce the 3 million tons of plastic waste generated by the country every year [10]. While the Republic of Ireland reported that the tax imposed on plastic bags has reduced its consumption significantly by more than $90 \%$ and changed consumer behaviour about disposable plastic bags [11], countries such as Italy, Denmark and the United Kingdom have recorded little or no achievement [9]. This has been attributed to the approach taken by these countries in implementing their various policies and regulations as it relates to plastic consumption. Their various approaches have given little appetite for either taxation, regulations or legislation as a preferred mechanism to modify consumer behaviour in relation to plastic bag use [12].

According to the learning theory put forward by Skinner [13], changes in behaviour evolves because of occurrence in the form of events, which an individual must respond to. The theory is based upon the conceptualization that changes in behaviour follow from learning. The author argued that changes in behaviour could either be of positive or negative

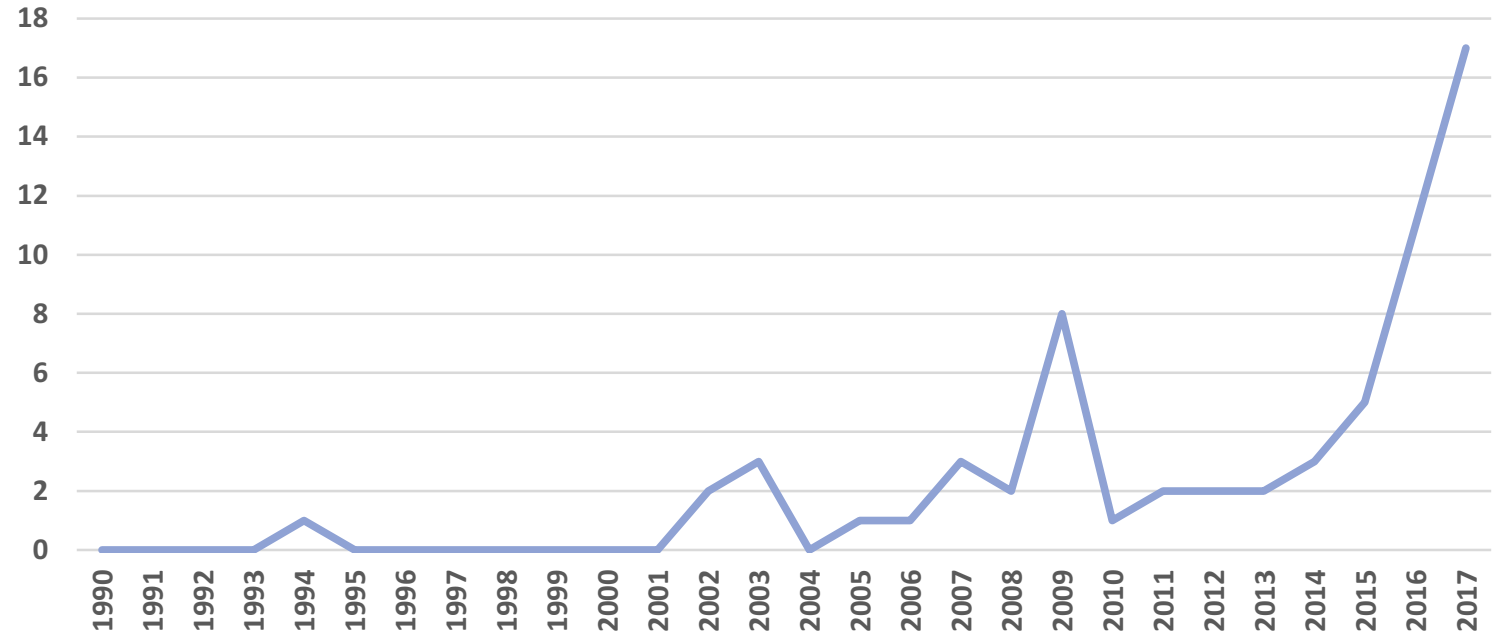

Number of regualtions on plastic bags, styrofoam and other plastic utensils that entered into force

Fig. 1 Estimated number of new regulations on single-use plastics entering into force at the national level worldwide [8] 
consequences. Jakovcevic et al. [14] added that positive results are said to occur in behaviour, when the probability of this behaviour increases, while the likelihood of occurrence decreases when negative consequences occur. This view further suggests that behaviour that is positively motivated and supported will reoccur, while behaviour tend to remain unchanged when there is a lack of motivation and support. Skinner' theory offers insight into why the different international government initiatives on single-use plastics in the form of taxation, regulations or legislation produce different results.

While some of these initiatives have focused on motivating the consumers in recycling single-use plastics, a majority have given little or no attention to encouraging and supporting consumers. For example, the Irish initiative on plastic use was hailed for its outstanding result. It modified consumer behaviour to cut the country's plastic use by over $90 \%$ and generated millions of euros in revenue for the government [11]. On the contrary, countries such as the United Kingdom have had little or no influence on consumer behaviour. This has been attributed to the United Kingdom's implementation of voluntary action to single-use plastic recycling instead of imposing taxation or legislative regime [9]. Likewise, Denmark introduction of a tax regime in 1994, which is ultimately absorbed by the retailer as opposed to being charged on the consumers had no impact on their behaviour. These views further suggest that there is a significant relationship between government implemented initiatives and consumer changing behaviour.

Therefore, the review aims to examine the effectiveness of the public policy, initiative or government regulations on population behaviour against single-use plastic bags consumption. The study will synthesise the existing evidence regarding government regulations targeted at changing shoppers' behaviour and public against the use of bio-degradable products such as plastic bags. The outcome will explain critical questions concerning the relationship between government regulations and behaviour change against plastic bags usage by considering the types of regulation that are most effective; duration for regulation to impact consumption; whether the consumption impacts are short or long term; the trade-off or rebound effects involved; the similarity of divergence of effects per plastic-type or product regulated; the thematic focus of the evidence found such as economical, health or environmental; and regional differences of effectiveness.

\section{Methods}

\subsection{Study selection}

As indicated in Table 1, only studies analysing national-level regulations regarding single-use plastic bags were included. In some countries, sub-national regulation was adopted first, and as the policy gained salience through the country, it was then later adopted at the national level. Furthermore, studies that analysed regulation inclusive of policy and economic instruments were considered. Studies that analyse soft-policy or international agreements were not considered. Included are studies published between January 01, 2000 and November 30, 2019. This is because most contemporary single-use plastic bags regulations have been adopted in this millennium. Hence, their impact on consumption behaviour should be analysed in the context of current society. Finally, only studies written in English and peer reviewed journal articles were included, while publications by agencies of government or intergovernmental were excluded. Also included are both qualitative and quantitative primary studies.

\subsection{Search strategy and terms}

Using the inclusion and exclusion criteria discussed above, the search terms and strings were developed. See Table 2 for details. We performed the search in Google Scholar, ScienceDirect, BASE Bielefeld, PubMed Central, De Gruyter, Sage Journals, Taylor \&

Table 1 Study selection (inclusion and exclusion)

\begin{tabular}{ll}
\hline Inclusion criteria & Exclusion criteria \\
\hline Regulatory policy and economic instruments & Sub-national regulation \\
Any single-use plastic regulation at the national level & Other languages besides English \\
Goal of regulation: to influence consumption & Literature published before Jan 01, 2000 and after Nov 30, 2019 \\
English language only & News or smaller NGO publications \\
Literature published between Jan 01, 2000 and Nov 30, 2019 & Partial impacts, such as littering oceans \\
Peer reviewed journal articles & Recycling policies \\
& Grey literature and reports
\end{tabular}


Table 2 Search terms

\begin{tabular}{|c|c|c|c|c|c|}
\hline regulat* & interven* & ban* & $\mathrm{lev}^{*}$ & $\operatorname{tax} *$ & law \\
\hline \multicolumn{6}{|l|}{ AND } \\
\hline plastic* & single-use & bag & & & \\
\hline \multicolumn{6}{|l|}{$A N D$} \\
\hline affect* & effect* & Impact* & influen* & reduc* & increas* \\
\hline low* & shrink* & demin* & & & \\
\hline \multicolumn{6}{|l|}{ NOT } \\
\hline surgery & Medicine & Biology & Cell* & Perception & marine \\
\hline
\end{tabular}

Francis, Springer Journals, JSTOR, Wiley-Blackwell Online, the Journal of Resources, Conservation \& Recycling, and the Journal of Waste Management. The search terms were utilized to construct appropriate search strings for the literature retrieval using Boolean logic. Search terms were exclusively applied in English and had to be adjusted to fit the different portals' varying and limited retrieval modalities. Search findings were imported and managed in a Citavi cloud account, to which all reviewers had access.

\subsection{Data extraction}

A data extraction tool was created in Microsoft Excel using the Cochrane handbook for Systematic Reviews and the Centre for Reviews and Dissemination's Systematic Reviews: CRD's Guidance for Undertaking Reviews in Health Care [15, 16]. The key study characteristics were extracted using Citavi feature to attribute keywords, categories and groups, and after that, synergized in an Excel form. Data on government regulations effectiveness, behaviour change, and impacts were extracted. A main extraction matrix was created. It included extraction of analytical indicators such as types of government intervention or regulations and their respective countries, the effectiveness of the interventions, study designs used in each study, sample size and total participants included, primary and secondary outcome, quality of evidence and risk of bias in included studies. The second extraction matrix involved types of regulation that was most effective; behaviour change time lag; how immediate and long term the intervention affect behaviour; the losses as a result of the regulations or intervention; categorising the evidence found into economical, health, environmental; and how the effectiveness of these interventions or regulations differs across countries assessed.

Four authors (SV,TMA, UAO and SR) independently extracted the final included studies based on the studies' geographical origin, which were then vetted by GCA, OO and AO to confirm the data and matrix categories. Discrepancies were discussed and resolved jointly among all authors; and where needed, the original studies were reviewed to resolution.

\subsection{Study quality assessment}

Each included studies' quality was assessed using the Grading of Recommendations, Assessment, Development and Evaluations (GRADE) approach for rating evidence of study $[16,17]$. GRADE offers a rating system that provides reviewers with a framework to rate the quality of evidence and, in turn, the extent of confidence the reviewers should have regarding the estimates of the evidence's effect. GRADE classifies the quality of evidence into one of four categories namely: high, moderate, low and very low: and was applied (through downgrading or upgrading factors) to assess each study (Tables 3 and 4 provide definition and indicators for allocation).

\subsection{Data analysis}

In a systematic approach, all analysed included studies were extracted, reviewed and reported. Except for insignificant or non-applicable items, the Preferred Reporting Items for Systematic Reviews and Meta-Analyses (PRISMA) checklist was used to synthesize and report findings $[18,19]$.

\section{Results}

Figure 2 below visualised sources of final included studies that meets the review criteria per country across the continents. 
Table 3 Factors that decrease/ increase quality of body of evidence [16]

Downgrading factors
Limitations in the design and implementation of studies suggesting high likeli-
hood of bias
Indirectness of evidence (PICO)
Unexplained heterogeneity or inconsistency of results

Imprecise results (wide confidence intervals)

High probability of publication bias
Upgrading factors

Large effect-size

Dose-response effects Confounding factors underestimate effect

Table 4 Context on rating evidence [17]

Quality level Current definition

High We are very confident that the true effect lies close to that of the estimate of the effect

Moderate We are moderately confident in the effect estimate: The true effect is likely to be close to the estimate of the effect, but there is a possibility that it is substantially different

Low Our confidence in the effect estimate is limited: The true effect may be substantially different from the estimate of the effect

Very low We have very little confidence in the effect estimate: The true effect is likely to be substantially different from the estimate of effect

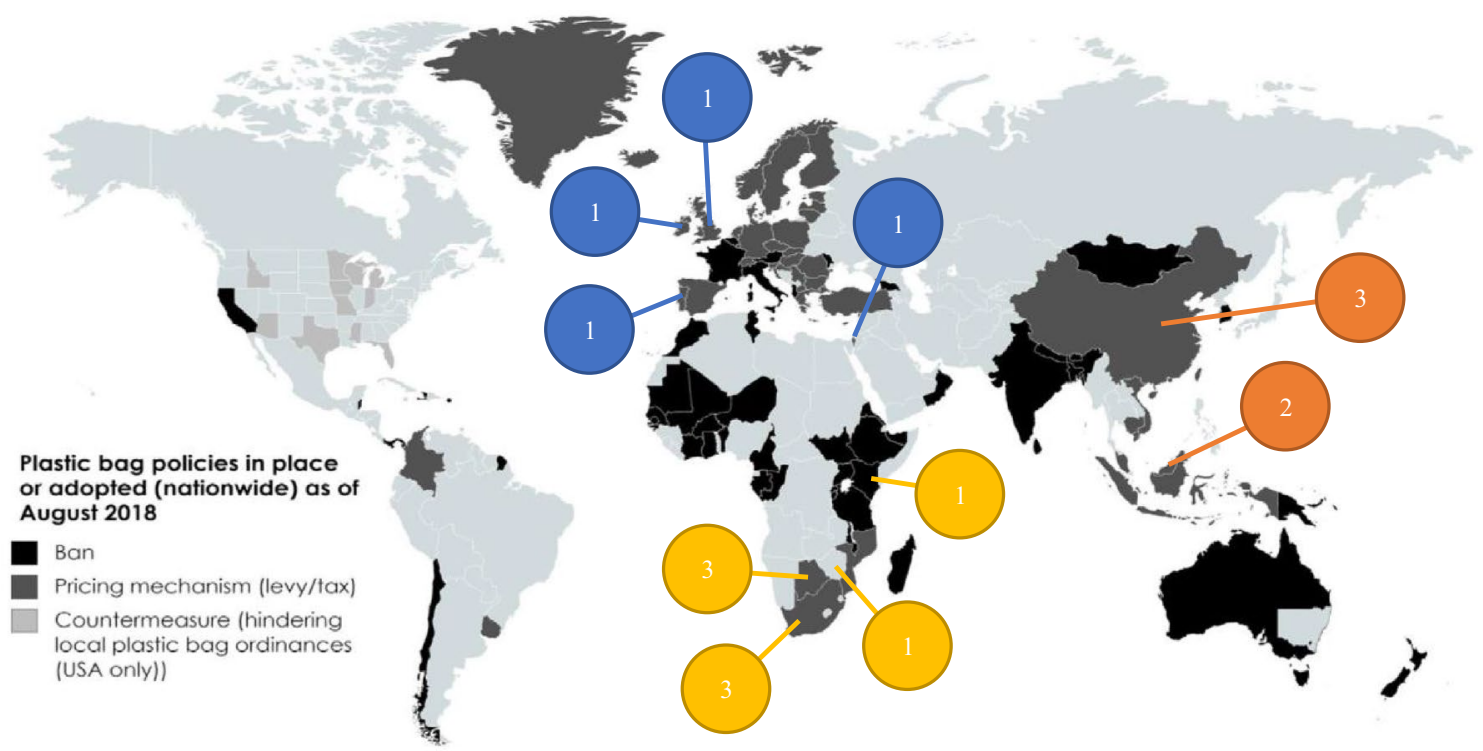

Fig. 2 Number of reviewed studies per country (colour illustrations) laid over the map 'Expansion of plastic carrier bag governmental initiatives from 2010 to August 2018' [20]

\subsection{Search results}

A total of 533,324 studies were retrieved across the 14 databases. However, 533,256 were excluded after screening for title and abstracts. After check and scan for a duplicate on the remaining 68 studies, 47 were final eligible ones. Of the final 47 studies, full-text studies were retrieved and assessed against all inclusion and exclusion criteria. In all, 17 studies were admissible after meeting all inclusion criteria, comprising studies that examined impacts or effects of government regulations on behaviour of the population in respect of plastic bags use. Figure 3 provides the PRISMA flow diagram illustrating process and results. 
Fig. 3 PRISMA flow diagram of selection process

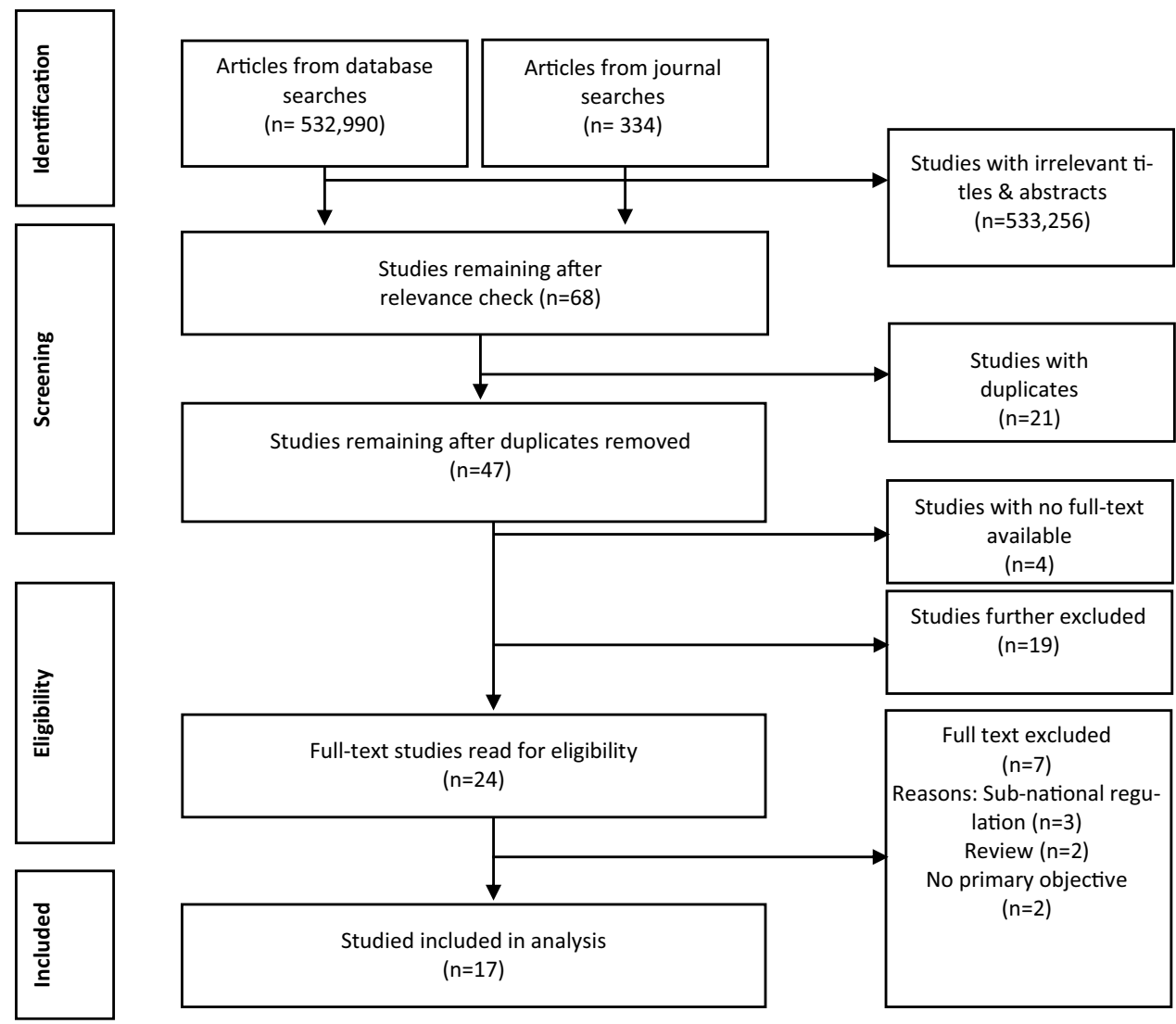

All included studies were published between the years 2007 and 2019. Of the 17 included studies, customer observation (4), customer surveys (8), ministry official interviews (1), data from retailers (3), and some using a mixed methodology (1). On geographical composition, there were studies analysing regulations in Africa (8), Asia (5), and Europe (4). Table 5 provided an outline of the characteristics of the included studies.

\subsection{Effects of plastic bag regulation by country case}

\subsubsection{Africa}

3.2.1.1 Botswana Intervention: A combination of bag ban and levy was introduced in 2007. Bags below 24 microns were banned, and retailers were instructed to set the levy price [21, 22].

Results: In the short-term, consumption dropped by $24 \%$ in the weeks after the ban and $50 \%$ by 18 months into implementation [21]. Ten years later, the researchers found that $86 \%$ of people say that the ban had no impact on their plastic bag use [23]. Further, based on a field survey with an average levy of BWP 0.44, if the levy were raised by BWP 1.00 the consumption would drop by $29.2 \%$. With increased BWP 2.00 , the consumption would drop by up to $64 \%$ [22]. This indicates that while long term behaviour change may not have resulted if the levies were increased to be more prohibitive, consumption would likely decrease.

3.2.1.2 Kenya Intervention: A ban on plastic carrier bags at retail centres came into force in August 2017 [24].

Results: After a year and a half of the ban, while it is not clear whether there was an overall reduction in consumption, $49 \%$ of survey respondents claimed that they take their own bags while shopping. This presumably has led to a decrease in single-use plastic bag usage. On the other hand, reusable bag ownership has nearly tripled from 4.32 bags to 12 bags per person. Out of this, reusable plastic bag ownership has doubled to 7.7 bags per person. The rise of reusable bag ownership is indicative of the changing shopping culture and is also related to behavioural aspects where shoppers either forget or bring lesser bags than they might need to retail stores. Thus, increased reusable bag ownership does not always translate to actual reuse (Fig. 4). 
Table 5 Characteristics of study findings

\begin{tabular}{|c|c|c|c|c|c|c|}
\hline S/No & Author/Year & Country & Study design & Target population & Intervention types & $\begin{array}{l}\text { Outcome } \\
\text { measure/effec- } \\
\text { tiveness }\end{array}$ \\
\hline 1 & Asmuni et al. 2015 & Malaysia & Post design & Shoppers & Tax on 1 weekday & $52.3 \%$ reduction \\
\hline 2 & Ayalon et al. 2009 & Israel & Pre-design & Households & Proposed Tax & $12 \%$ estimation \\
\hline 3 & Chitotombe 2014 & Zimbabwe & Post design & shoppers & Partial ban, levy & Not stated \\
\hline 4 & Convery et al. 2007 & Ireland & Post design & Shoppers and Households & Retailer Tax & $94 \%$ \\
\hline 5 & Dikgang et al. 2012a & South Africa & Pre- and post-design & Shoppers & Tax & $50 \%$ average \\
\hline 6 & Dikgang et al. 2012b & South Africa & Post design & Shoppers & Tax & $76 \%$ \\
\hline 7 & Dikgang and Visser 2012 & Botswana & Post design & shoppers & Partial ban, Tax & $50 \%$ \\
\hline 8 & Hasson et al. 2007 & South Africa & Post design & shoppers & Partial ban, Tax & $47.5 \%$ average \\
\hline 9 & Martinho et al. 2017 & Portugal & Pre and post-design & Shoppers & Tax & $74 \%$ \\
\hline 10 & Omondi and Asari 2019 & Kenya & Post design & shoppers & Ban & $\begin{array}{c}49 \% \text { stated } \\
\text { using own } \\
\text { bags while } \\
\text { shopping }\end{array}$ \\
\hline 11 & Thomas et al. 2019 & England & Pre- and post-design & Shoppers & Tax & $25 \%$ \\
\hline 12 & Xing 2009 & China & - & - & Partial ban, Tax & Not stated \\
\hline 13 & Zen et al. $2013 \mathrm{~S}$ & Malaysia & Post design & Shoppers of NPB days & Tax on one weekday & Not stated \\
\hline 14 & Zhu 2011 & China & Pre- and post-design & Uncertain & Partial ban, Tax & Not stated \\
\hline 15 & Madigele et al. 2017 & Botswana & Post design & shoppers & Tax & $29.20 \%$ \\
\hline 16 & Mogomotsi et al. 2019 & Botswana & Post design & Shoppers & Partial ban, Tax & Not stated \\
\hline 17 & He 2012 & China & Pre- and post-design & Shoppers & Partial ban, Tax & $49 \%$ \\
\hline
\end{tabular}
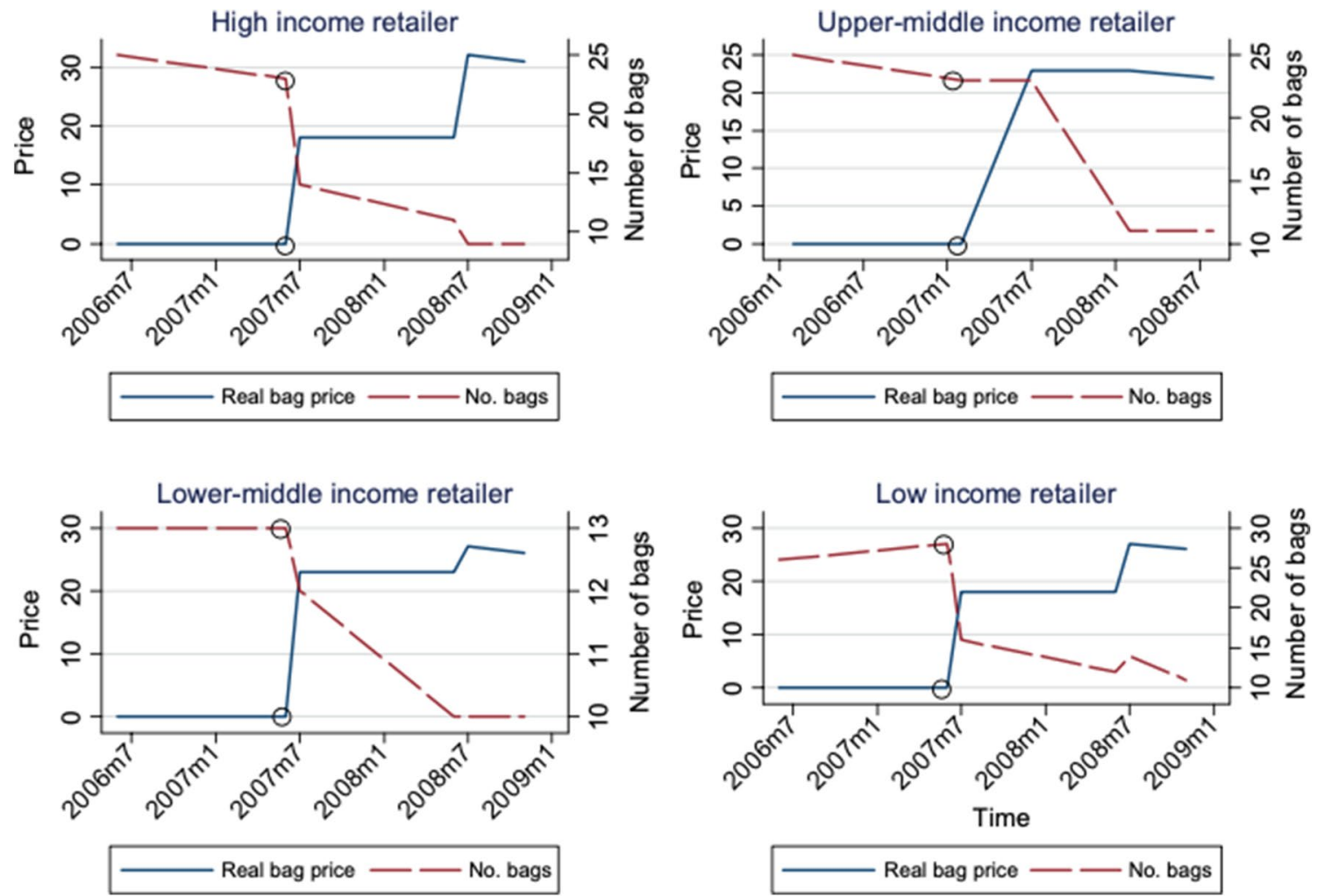

Fig. 4 Plastic bag consumption in Botswana [21] 
Fig. 5 Consumption of regulation targeted and excluded bags in China [28]

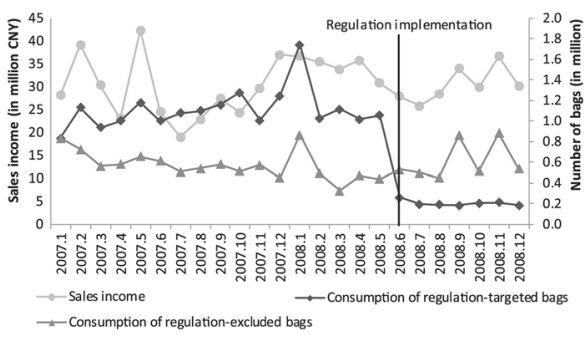

3.2.1.3 South Africa Intervention: In May 2003, regulation set the minimum thickness of plastic bags issued by retailers at 24 microns and limiting printing to $25 \%$ of the surface area of plastic bags ( $50 \%$ for environmentally friendly ink). Additionally, a nominal tax of 46-rand cents (US\$ 0.06) was imposed on new plastic bags sold by retailers [12]. However, this only lasted for 3 months, after which due to pressure from plastic bag manufacturers the tax fell, and retailers started charging variable prices [25].

Results: In the short term (in the first 3 months after the levy), there was a sharp decline in plastic bag demand by approximately $60-90 \%[25,26]$. However, in the medium term there was a revival in demand for bags coinciding with the removal of the fixed levy. Between August 2003 to June 2004, plastic bag demand varied between 20 and $80 \%$ of original consumption levels [26]. Over a 6-year period, from 2003 to 2009, plastic bags per real Rand 1000 of shopping fell by approximately $44 \%$. Out of this, the high-income retailers experienced a $57 \%$ decline, and the low-income retailers experienced a 50\% reduction [12]. Given the steady increase in plastic bag demand, despite rising nominal and real price per bag, it is expected that consumption will continue to increase, and the plastic littering problem will persist. Overall, therefore, price elasticity of demand has been unexpectedly low in the long term [25]. This suggests that the policy has failed partially. Regulations governing the thickness of plastic bags did not have an impact on consumption and demand [26].

3.2.1.4 Zimbabwe Intervention: A combination of ban and taxes were instituted in 2010. Bags below 30 microns were banned, and one South African Rand (US\$0.10) tax was placed on new bags [27].

Results: The GRADE rating for this study was low due to study design flaws and lack of standardized presentation of the data collected. However, one finding of the interviews was that consumption of plastic bags reduced for a short time, but shortly returned to pre-tax levels.

3.2.1.5 Overall assessment for Africa Botswana and South Africa put in place similar regulatory instruments, such as the proscription of bags below 24 microns and levy on the sale of plastic bags above 24 microns. Zimbabwe also put in place similar regulations with the only difference being bags below 30 microns were banned, and a price was placed on new bag sales above 30 microns. In all three cases, the key finding was that consumption of plastic bags reduced in the short term, immediately following the regulation. However, the impact of the regulation wasn't sustained in the long term. In Botswana's case, it is hypothesized that perhaps an increase in the levy will drive down consumption. In South Africa, on the other hand, despite increasing levies, consumption patterns have followed an upward trend. This low elasticity of plastic bags could be due to a combination of factors. The relatively low price of bags in terms of consumer incomes could be a factor. Additionally, low consumer awareness regarding the price of the bags might be contributing to the low-price elasticity [25]. Kenya, on the other hand, adopted a more extreme regulatory system by banning all plastic carrier bags. The GRADE rating for the Omondi and Asari [24] study is very low and it is unclear whether the ban is applicable to all plastic bags irrespective of thickness. Regardless, single-use plastic consumption appears to have decreased, although the overall impact on plastic use is unknown since reusable plastic bag ownership has nearly doubled.

\subsubsection{East Asia}

3.2.2.1 China Intervention: A levy was introduced in June 2008, through a "nationwide regulation requiring all retailers to charge for plastic shopping bags" [28]. Figure 5 shows how nationwide regulation in China influenced consumption behaviour of plastic bags.

Results: Half a year after implementation, "the average number of bags consumed monthly fell from around one million to 0.2 million" [28]. A self-reported consumption reduction of $49 \%$ was observed in consumer surveys in two differently wealthy cities. The effect was immediate, though the less wealthy city continues to consume more plastic bags. There 
are differences among consumer groups. Positive regulation perception correlated with effectiveness. Enforcement is inefficient at informal markets [29]. Substitutes for plastic bags may be missing [30].

3.2.2.2 Malaysia Intervention: A tax was introduced in January 2011 through a consumption tax of US\$0.06 per bag on Saturdays ("No Plastic Bag Campaign" day).

Results: Studies [31, 32] did not assess the ex-ante consumption, but only the ex-post-consumer behaviour. As such, no variance in consumption can be detected.

3.2.2.3 Overall assessment for East Asia Because only the studies reporting on China discuss significant evidence, a broad statement of the effectiveness of regulation in East Asia cannot be made and suggest a further research.

\subsubsection{Europe}

3.2.3.1 Ireland Intervention: A tax of $€ 0.15$ was imposed on consumption of plastic bags in 2001 [33].

Result: The tax was fixed to change consumer behaviour towards the use of plastic bags in Ireland, and not necessarily to generate revenue. This emboldened the Irish government set the tax so high that it would deter consumers from indiscriminate use of plastic bags. The tax of $€ 0.15$ was multiple folds higher than the maximum price cited in a survey that was carried out before the levy was implemented, which only $8 \%$ of respondents were willing to pay. However, the legislation is said to have recorded huge success in the country, with the positive effect cutting across different stratum of the society including retailers who were not giving plastic bags for free. According to the study, there was a drop of about $94 \%$ in the consumption of plastic bags within a few years of coming into effect. Also, plastic bags, which constituted about $5 \%$ of litter in Ireland pre-legislation in 2001 dropped to $0.32 \%$ of litter in $2002,0.25 \%$ in 2003 and $0.22 \%$ in 2004 . While there was a small rebound after a few years, probably because consumers got used to the levy, the legislation is still considered a major success.

3.2.3.2 Israel Intervention:The study was conducted using a proposed levy of NIS 1 (US\$0.07) on the purchase of plastic bag [34]. This was an estimation effect study.

Result: Authors stated that $6 \%$ of the annual plastic bag consumption was used for outdoor activities, hence could become litter if not properly disposed afterwards. The authors further made the case that even if the proposed levy of $\$ 0.07$ was increased by $400 \%$, a sizable number of consumers in Israel would still use plastic bags, particularly the people that deploy it for outdoor activities. Hence the litter ratio of $6 \%$ might remain stagnant regardless of the levy. These arguments downgrade the author's view on the proposed tax on plastic bags, and they subsequently suggested that any gain the government aims to generate from imposing levy on the use of plastic bags would be lost in the consumer surplus deprivation that would hit the country. Instead, the study recommended explanatory and educational measures that would encourage reduction in consumption of plastic bags and not impact the consumer surplus adversely.

3.2.3.3 Portugal Intervention: A $€ 0.10$ tax on plastic bag consumption which was implemented in February 2015 [35].

Result: In a bid to reduce the consumption of plastic grocery bags in Portugal and in turn reduce the potential contribution to marine litter, the government introduced a plastic bag tax of $€ 0.10$ which was implemented in February 2015. The study analysed the effect of the plastic bag tax on consumer and found out that there was a $74 \%$ reduction in the consumption of plastic bags within the first few months of implementation. During the same timeframe, there was a $61 \%$ increase in the purchase of reusable plastic bags, but a corresponding $12 \%$ increase in the consumption of garbage bags. There was also an insignificant difference between the coastal area and the non-coastal area that were sampled, which shows that the legislation affected the entire country almost equally. Furthermore, supermarkets and hypermarkets offered alternatives to customers including the use of their trolleys to move purchased goods.

\subsubsection{England Intervention: An introduction of $€ 0.05$ levy on the purchase of plastic bags [36].}

Result: The study analysed the consumer reaction to $\mathrm{E} € 0.05$ tax on the use of plastic bag in England, and how the success in the legislation laid a foundation for further policies targeting a reduction in environment pollution. The study claimed that prior to the levy, 55\% of shoppers in England used plastic bags given by retailers-the number however fell to $21 \%$ within 6 months of the implementation. While the study indicated a slight demographic pattern to the consumption of plastic bags, the difference was negligible. The study also projected a reduction in consumption in plastic bags in future comparable to what was applicable in both Wales and Scotland, particularly as there was a comparable short-term reduction in all three countries. 
3.2.3.5 Overall assessment for Europe From the four studies analysed above, with three focusing on ex-post analysis, it was deduced that taxes on European shoppers as a way of changing behaviour against plastic bags consumption has been considerably successful. There was $82 \%$ compliance rate by consumers in the use of plastic bags in Europe. It is also puzzling that while the levy was relatively smaller in England in comparison the other countries reviewed, it had an almost equal effect compared to Portugal. This could mean that the amount of the tax was not the important tool, but the idea of taxing users, and the satisfaction that comes with doing good to the environment. Israel though could be regarded as a deviant case, as the imposition of taxes may not affect the consumption of plastic bags. However, the argument was based on outdoor litter and not necessarily the overall consumption.

\subsection{Study quality, risk of bias, and quality of evidence}

The evidence of quality using GRADE was translated into numeric and depending on the quality category of studies, it is either downgraded or upgraded by points: high (0-1), moderate (2-3), low (4-5) and very low (>5). Table 7 in Appendix explained the points. The 17 included studies varied in their GRADE scores-two studies received a 'very low'score, four received a'low' score, six received a 'moderate' score, and five received a 'high' score. As outlined in Table 3, seven criteria were used for assessment across all studies, downgrading/upgrading the level of confidence:

1. The type of design and the inherent likelihood of bias was considered. Randomized customer observation at pointsof-sale were considered to be of the lowest likelihood for bias and unstructured interviews with government officials were considered to be of the highest likelihood of bias.

2. The type of sample (retailer data, customers, ministry officials) also contributed to downgrading based on sample size (the higher, the better).

3. The funding sources, if any, were taken into consideration for potential influence on study design or analysis.

4. The degree of indirectness of evidence was evaluated based on how removed the sample type was from the primary objective of consumer behaviour.

5. The inconsistency of results was evaluated based on consistency of reported findings throughout the study.

6. The precision of results was considered based on the number of events or participants included in the study and the accompanying specificity of results reported.

7. Publication bias was assessed based on the presence of selective reporting and justification practices.

Because of the generally overly heterogeneous use of methodology and the lack of control groups and small sample sizes in the selected studies' design, it was difficult to apply upgrading factors. We therefore restricted the quality assessment to the application of downgrading factors only, giving each one point for a mild limitation and two points for a grave limitation regarding the factors: study design, indirectness, inconsistency, imprecision, and publication bias. This yielded the below ranking (see below Table 6) of quality of evidence in each study.

\section{Discussion}

\subsection{National regulation and reduction in plastic bags consumption}

Although explicitly setting the scope of the systematic review on national regulations addressing any type of single-use plastic, the only policy evaluations that matched the inclusion and exclusion criteria concerned regulations of plastic bags. Most of the 17 selected publications assessed the efficacy of regulation that was a combination of a ban on plastic bags below a certain thickness threshold in combination with sales tax. The applied method of assessing regulation effectiveness varied substantially among the studies, ranging from ad-hoc demand estimations over questionable consumer surveys to a few compelling and comprehensive multi-method ex-post evaluations. Additionally, sampling and control techniques were done very differently, so that the obtained results need to be treated carefully. Due to this breadth in method type and quality, only eight studies manage to make an empirical conclusion on the effectiveness of the assessed regulation. As illustrated in Fig. 6 , all these studies detect anticipated behaviour change through lowering consumption, varying between around $20 \%$ and $90 \%$. 
Table 6 Quality assessment of selected studies

\begin{tabular}{lllll}
\hline$\#$ & Publication & Method & $\begin{array}{l}\text { Total deduc- } \\
\text { tions }\end{array}$ & Quality assigned \\
\hline 1 & Asmuni et al. 2015 & Ex-post observation & 5 & Low \\
2 & Ayalon et al. 2009 & Ex-ante feasibility survey & 3 & Moderate \\
3 & Chitotombe 2014 & Ex-post interview & 4 & Low \\
4 & Convery et al. 2007 & Ex-post survey, interview & 2 & Moderate \\
5 & Dikgang et al. 2012a & Pre- and post survey & 1 & High \\
6 & Dikgang et al. 2012b & Ex-post industry data & 2 & Moderate \\
7 & Dikgang and Visser 2012 & Ex-post interview & 2 & Moderate \\
8 & Hasson et al. 2007 & Ex-post industry data & 2 & Moderate \\
9 & Martinho et al. 2017 & Pre- and post survey & 1 & High \\
10 & Omondi and Asari 2019 & Ex-post survey & 8 & Very low \\
11 & Thomas et al. 2019 & Pre- and post multi method & 0 & High \\
12 & Xing, 2009 & Review & 6 & Very low \\
13 & Zen et al. 2013S & Ex-post survey & 4 & Low \\
14 & Zhu 2011 & Pre- and post survey & 4 & Low \\
15 & Madigele et al. 2017 & Ex-post survey & 0 & High \\
16 & Mogomotsi et al. 2019 & Ex-post survey & 2 & Moderate \\
17 & He 2012 & Pre- and post survey & 1 & High \\
\hline
\end{tabular}

Fig. 6 Consumption behaviour pattern: pre-intervention and post intervention. The data points are derived from individually stylized information $[12,21,25,26,28,33,35$, 36]

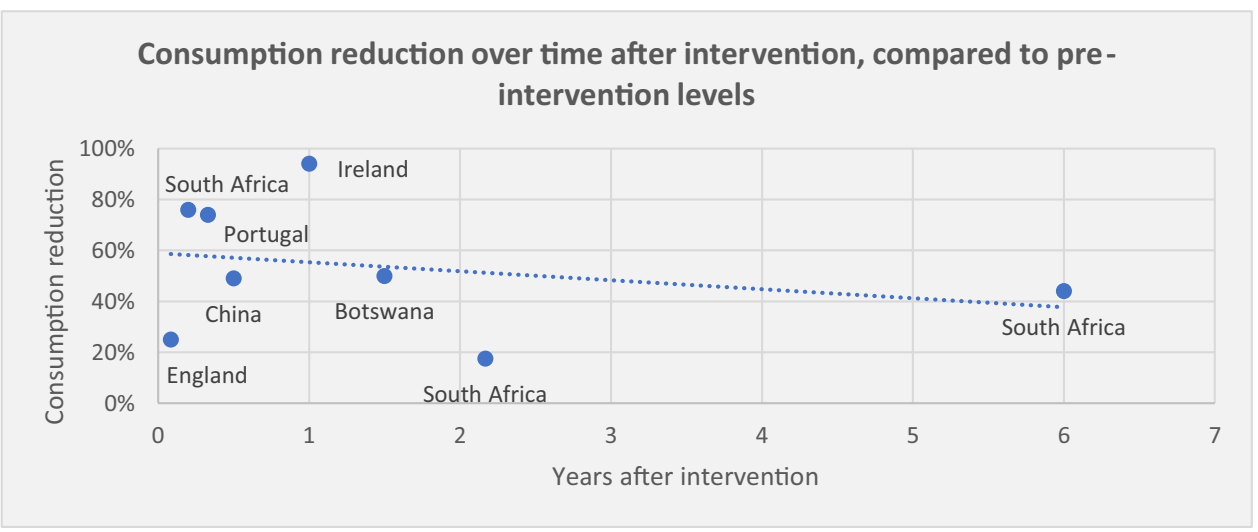

\subsection{Assessing the most effective regulations}

Whilst it is evident from the study findings that regulations based solely on the thickness of plastic bags will not reduce plastic bags consumption as in the case of South Africa, regulations focused on banning plastic bag usage, charging tax and levy are seen to be significantly effective in reducing plastic bags consumption behaviour; as in the case of Portugal and Ireland. Likewise, a combination of regulation such as imposing a ban and taxes were found to reduce plastic bag consumption behaviour significantly in the case of Botswana and Zimbabwe. More important, the intervention using taxes are considered more effective when it is high enough to prohibit consumption behaviour as in the case of Botswana and Ireland.

Based on the studies reviewed and the findings of this study, it is rather difficult to conclude that one regulation is more effective than the other considering that different approaches, administration process and implementation procedures have been considered by the different regulatory countries. For example, how the imposed tax or levy is administered has significant influence on its success. While imposed taxes administered by retailers has been considered mostly effective in the short and medium term as in the case of Botswana and China, also those administered by the government as in the case of Ireland has been found to be effective in both the short and the long term as well. Also, it is worth mentioning that the attitude, perception and behaviour of consumers toward a formulated regulation will significantly influence its successful implementation. This is because in some instances, the amount of the levy was not the important tool but the idea of satisfaction that comes with doing good to the environment. 


\subsection{Short and long-run impacts on behaviour}

Most reviewed studies reported behaviour was affected immediately government interventions came into force, though already including varying effectiveness. Because most empirical studies assess regulation outcomes up to two years after implementation, long-term effects on behaviour can only be estimated. Figure 5 made such an attempt by plotting the observed consumption reduction in a given country against the years. It shows that, over period and after an initially stronger consumption reduction, plastic bag consumption rose again, on average, creating a rebound. Although based on too few data points to be significantly conclusive, the trendline suggests that over a period of 6 years, the aggregate effectiveness of six national plastic bag regulations has fallen by around $20 \%$ points.

The strongest support for this observation comes from the case of South Africa. The three different studies of high and moderate quality, which investigate the country's intervention, yielded effectiveness values with a rebound pattern. One of the studies already observes a rebound pattern over the course of only a few months [26]. A similar case is Botswana, where people reported no impact on their plastic bag use 10 years after intervention, although an earlier study shows clear reductions in the 1 st years $[21,23]$. Nonetheless, these evidences are not strong enough to assume that the effectiveness of plastic bag regulation generally decreases over time.

\subsection{Explaining intervention's counter effectiveness}

Besides the notion that the best documented country case shows signs of plastic bag consumption behaviour increasing again over time long after intervention, some studies claim to observe trade-offs that have hindered regulations from delivering their intended effects. This ranges from implementation issues and low enforcement in different market settings across a country, over consumer differences to simple substitution effects. Especially the latter is remarked as a substantial deficit of the reviewed regulations $[32,35]$. It entails that, while the consumption of some plastic bags decreased the consumption of others increased. For example, while regulation-targeted plastic bags are used significantly less after the intervention, consumers are quick to substitute them for other types of bags not affected by a ban or levy. In other cases, scholars observe an increased use of plastic bags for other purposes or re-use, such as an increase in trash bag purchases, for which regular shopping bags were previously used (Figs. 3, 6).

Lastly, consumers who are disincentivized by regulation to buy plastic bags to carry shopping purchase are seen to resort to increasingly buying pre-packaged and plastic-wrapped products. These examples demonstrate that while the targeted plastic products of a regulation have generally been positively affected by a consumption reduction, the overall consumption of similar single-use plastic may have increased in turn. This suggests that the aggregate consumption of single-use plastic is affected not as severely or may even balance with pre-intervention levels. There is hardly any study that have directly juxtapose the measured effects on regulation-targeted bags to non-targeted bags or aggregate figures, except for example, China, where a positive net effect in total plastic bag consumption was observed during the 1 st months after the intervention [28].

\subsection{Winners and losers arising from regulation of non-biodegradable plastic bags use}

Only few studies have been designed to deliberately compare consumption-effects on different groups of market actors. Among those that do, a mixed finding emerged. A more common observation is that taxes or levies affects the less well-off citizen harder and they are less flexible to adjust their consumption behaviour. For example, the people in the less prosperous Chinese city Guiyang "consume 2.7 more new bags than those in Beijing ex ante, while this consumption difference increases to 4.8 new bags ex post." [28]. Similarly, in Zimbabwe, the burden has mainly been on the elderly and the poor [27]. As a counterexample, the interventions in England created no substantial cleavages between gender, age or income [36].

Contrasting these findings to other reviews on single-use plastic regulation $[4,20,37,38]$, this study discovers some country cases and studies have not been retrieved by this review literature search. However, these concerned studies are mainly grey literature and journalistic references, such as in Nielsen et al. [20]; which were excluded based on quality of evidence. On the other hand, other reviews confirm our recommendation of a combination of policy tools, while also stressing that long-term effects are yet uncertain. While generally employing a more positive outlook, other reviews agree that both research and policy needs to be improved, to truly make a meaningful global impact on the climate or environment-friendly behaviour. 


\title{
5 Conclusion
}

Parallel to the increasing global saliency towards environmental issues and climate change, states have moved to regulate single-use plastic bags in the last two decades, in order to promote behaviour that support the former courses [4, 20]. Despite wide differences in publication quality, methods and focus, this review found that, a few interventions have led to behaviour change against consumption of plastic bags. Although, effectiveness of the intervention varies across countries and between 20 and $90 \%$. However, many studies identified trade-offs that put the overall effectiveness of plastic bag regulation into question. The review observes potential substitution effects; where consumers switch from their consumption of regulation-targeted bags to other types of single-use plastics. The net effect of government interventions on aggregate plastic consumption is thus ambiguous and complex. Out of the 172 countries with variation of single-use plastic regulation in place, only 10 were included in the 17 studies under this review. Thus, there is a wide gap in knowledge regarding the status of the policy in the remaining continents such as in North and South America, where only states and cities are making effort at tackling the use of single-use plastics. This create opportunities for further and extensive research to be carried out on sub-national regulations on single-use plastic bags and their impacts on consumer behaviour.

In conclusion, given the relatively low share of plastic bags within the entire amount of plastic produce and waste, the eventual difference in avoided plastic waste is small, if not 'negligible', as predicted in Israel [34]. Hence, we may not confirm that plastic bag regulations substantially contribute to addressing climate change and the environmental agenda, but it thus contributes in significant ways; and changing behaviour through public policy or regulations proves to be an effective instrument. Further study is therefore needed to examine or explore the contribution of single-use plastic bags regulations to climate change challenges. More so, as reiterated previously, a deliberate review focused on the North America sub-national and local single use plastic bags regulations, in the absence a national regulatory strategy is a research gap that needs to be filled.

\begin{abstract}
Authors' contributions (1) GCA supported the development of the background, search strategy, screening of papers against eligibility criteria, quality of evidence in studies, general summary of findings and analytical discussions. (2) TMA supported the development of the background, designed the GRADE tool, undertook search, screened search results, screen retrieved papers against eligibility criteria, appraised quality of papers, extracted data from articles, analysed data, interpreted data, summarised findings for African studies. (3) UAO undertook searches, screened search results, screen retrieved papers against eligibility criteria, appraised quality of papers, extracted data from papers, summarised findings for European studies. (4) SR designed search criteria, designed data extraction, undertook searches, screened search results, screen retrieved articles against eligibility criteria, appraised quality of articles, extracted data from articles, wrote to authors of articles for additional information. (5) SV designed the search strategy and protocol, undertook searches, screened search results, organized retrieval of articles, screen retrieved papers against eligibility criteria, appraised quality of papers, extracted data from papers, summarized findings for East Asian studies. (6) OAO, AO supported summary analysis, background literature review, contributed to the discussion section and aligned the article to journal requirements. All authors read and approved the final manuscript.
\end{abstract}

Funding Open Access funding enabled and organized by Projekt DEAL. No further funds, grants, or other support was received.

Availability of data and materials The datasets generated and/or analysed during the current study are available upon request.

Ethics approval and consent to participate Not applicable.

Consent for publication All authors read and consent to the final manuscript.

Competing interests The authors declare that they have no competing interests.

Open Access This article is licensed under a Creative Commons Attribution 4.0 International License, which permits use, sharing, adaptation, distribution and reproduction in any medium or format, as long as you give appropriate credit to the original author(s) and the source, provide a link to the Creative Commons licence, and indicate if changes were made. The images or other third party material in this article are included in the article's Creative Commons licence, unless indicated otherwise in a credit line to the material. If material is not included in the article's Creative Commons licence and your intended use is not permitted by statutory regulation or exceeds the permitted use, you will need to obtain permission directly from the copyright holder. To view a copy of this licence, visit http://creativecommons.org/licenses/by/4.0/.

\section{Appendix}

See Table 7. 
Table 7 The applied four levels of evidence

\begin{tabular}{lc}
\hline Quality level & $\begin{array}{l}\text { Number of } \\
\text { downgrading } \\
\text { points }\end{array}$ \\
\hline High & $0-1$ \\
Moderate & $2-3$ \\
Low & $4-5$ \\
Very low & $>5$ \\
\hline
\end{tabular}

\section{References}

1. Thompson RC, Swan SH, Moore CJ, vom Saal FS. Our plastic age. Philos Trans R Soc Lond Ser B Biol Sci. 2009;364(1526):1973-6. https:// doi.org/10.1098/rstb.2009.0054.

2. Geyer R, Jambeck JR, Law KL. Production, use, and fate of all plastics ever made. Sci Adv. 2017;3(7):e1700782. https://doi.org/10.1126/ sciadv.1700782.

3. Parker, L. Plastic bag bans are spreading. But are they truly effective? National Geographic. 2019. https://www.nationalgeographic.com/ environment/2019/04/plastic-bag-bans-kenya-to-us-reduce-pollution/\#closeRitch. Retrieved 12 Dec 2020.

4. Excell C, Salcedo-La Viña C, Worker J, Moses E. Legal limits on single-use plastics and microplastics: a global review of National Laws and Regulations. United Nations Environment Programme (UNEP). 2019. https://www.unenvironment.org/resources/report/legal-limitssingle-use-plastics-and-microplastics.

5. Derraik JGB. The pollution of the marine environment by plastic debris. Mar Pollut Bull. 2002;44(9):842-52. https://doi.org/10.1016/ S0025-326X(02)00220-5.

6. Gregory RM. Plastics and South Pacific Island shores: environmental implications. Ocean Coast Manag. 1999;42(6-7):603-15. https://doi. org/10.1016/S0964-5691(99)00036-8.

7. Horton AA, Walton A, Spurgeon DJ, Lahive E, Svendsen C. Microplastics in freshwater and terrestrial environments: evaluating the current understanding to identify the knowledge gaps and future research priorities. Sci Tot Environ. 2017;586:127-41. https://doi.org/10.1016/j. scitotenv.

8. Giacovelli C. Single-use plastics: a roadmap for sustainability. United Nations Environment Programme (UNEP). 2018. https://www.unenv ironment.org/resources/report/single-use-plastics-roadmap-sustainability. Retrieved 16 Dec 2020.

9. Brennan C, MacLeod C. Plastic bag politics: modifying consumer behaviour for sustainable development. Int J Consum Stud. 2009;33(2):168-74. https://doi.org/10.1111/j.1470-6431.2009.00749.

10. Griggs MB. Canada plans to ban single-use plastics by 2021. The Verge. June 10, 2019. https://www.theverge.com/2019/6/10/18659644/ canada-ban-single-use-plastics-bags-straws-2021.

11. British Broadcasting Company (BBC). Irish bag tax hailed a success. 2002. http://news.bbc.co.uk/1/hi/world/europe/2205419.stm. Retrieved 17 Sept 2020.

12. Dikgang J, Leiman A, Visser M. Analysis of the plastic-bag levy in South Africa. Resour Conserv Recycl. 2012;66:59-65. https://doi.org/10. 1016/j.resconrec.2012.06.009.

13. Skinner BF. Science and human behavior. New York: Macmillan; 1953.

14. Jakovcevic A, Steg L, Mazzeo N, Caballero R, Franco P, Putrino N, Favara J. Charges for plastic bags: motivational and behavioral effects. J Environ Psychol. 2014;40:372-80. https://doi.org/10.1016/j.jenvp.2014.09.004.

15. Centre for Reviews and Dissemination. CRD's guidance for undertaking reviews in healthcare (3rd ed.). Systematic reviews. University of York. 2009. https://www.york.ac.uk/media/crd/Systematic_Reviews.pdf.

16. Higgins JPT, Green S, editors. Cochrane book series. Cochrane handbook for systematic reviews of interventions. Wiley-Blackwell: Hoboken; 2008.

17. Balshem H, Helfand M, Schünemann HJ, Oxman AD, Kunz R, Brozek J, Vist GE, Falck-Ytter Y, Meerpohl J, Norris S, Guyatt GH. Grade guidelines: 3. Rating the quality of evidence. J Clin Epidemiol. 2011;64(4):401-6. https://doi.org/10.1016/j.jclinepi.2010.07.015.

18. Moher D, Liberati A, Tetzlaff J, Altman DG. Preferred reporting items for systematic reviews and meta-analyses: the PRISMA statement. PLoS Med. 2009;6(7):e1000097. https://doi.org/10.1371/journal.pmed.1000097.

19. Liberati A, Altman DG, Tetzlaff J, Mulrow C, Gøtzsche PC, et al. The PRISMA statement for re- porting systematic reviews and meta-analyses of studies that evaluate health care interventions: explanation and elaboration. Ann Intern Med. 2009;151:W65-94.

20. Nielsen TD, Holmberg K, Stripple J. Need a bag? A review of public policies on plastic carrier bags —where, how and to what effect? Waste Manag. 2019;87:428-40. https://doi.org/10.1016/j.wasman.2019.02.025.

21. Dikgang J, Visser M. Behavioural response to plastic bag legislation in Botswana. S Afr J Econ. 2012;80(1):123-33. https://doi.org/10.1111/j. 1813-6982.2011.01289.x.

22. Madigele PK, Mogomotsi GEJ, Goemeone EJ, Kolobe M. Consumer willingness to pay for plastic bags levy and willingness to accept ecofriendly alternatives in Botswana. Chin J Popul Resour Environ. 2017;15(3):255-61. https://doi.org/10.1080/10042857.2017.1369243.

23. Mogomotsi PK, Mogomotsi GEJ, Phonchi ND. Plastic bag usage in a taxed environment: investigation on the deterrent nature of plastic levy in Maun, Botswana. Waste Manag Res. 2019;37(1):20-5. https://doi.org/10.1177/0734242X18801495.

24. Omondi I, Asari M. Impact of plastic bag ban on behavior and attitudes in Kenya. The 30th annual conference of JSMCWM, 2019, Article 7, 533-4. https://www.jstage.jst.go.jp/article/jsmcwm/30/0/30_533/_pdf/-char/ja. 
25. Dikgang J, Leiman A, Visser M. Elasticity of demand, price and time: lessons from South Africa's plastic-bag levy. Appl Econ. 2012;44(26):3339-42. https://doi.org/10.1080/00036846.2011.572859.

26. Hasson R, Leiman A, Visser M. The economics of plastic bag legislation in South Africa. S Afr J Econ. 2007;75(1):66-83. https://doi.org/10. 1111/j.1813-6982.2007.00101.x.

27. Chitotombe JW. The plastic bag 'ban' controversy in Zimbabwe: an analysis of policy issues and local responses. Int J Dev Sustain. 2014;3(5):1000-1012. https://isdsnet.com/ijds-v3n5-6.pdf.

28. He H. Effects of environmental policy on consumption: lessons from the Chinese plastic bag regulation. Environ Dev Econ. 2012;17(4):40731. https://doi.org/10.1017/S1355770X1200006X.

29. Zhu Q. An appraisal and analysis of the law of "plastic-bag ban." Energy Procedia. 2011;5:2516-21. https://doi.org/10.1016/j.egypro.2011. 03.432 .

30. Xing, X. Study on the ban on free plastic bags in China. J Sustain Dev. 2009;2(1):156-158. https://pdfs.semanticscholar.org/2d78/c1857 c4af970b0f291749a6feb59ad4f8f18.pdf.

31. Asmuni S, Hussin NB, Khalili JM, Zain ZM. Public participation and effectiveness of the no plastic bag day program in Malaysia. Procedia Soc Behav Sci. 2015;168:328-40. https://doi.org/10.1016/j.sbspro.2014.10.238.

32. Zen IS, Ahamad R, Omar W. No plastic bag campaign day in Malaysia and the policy implication. Environ Dev Sustain. 2013;15(5):1259-69. https://doi.org/10.1007/s10668-013-9437-1.

33. Convery F, McDonnell S, Ferreira S. The most popular tax in Europe? Lessons from the Irish plastic bags levy. Environ Resour Econ. 2007;38(1):1-11. https://doi.org/10.1007/s10640-006-9059-2.

34. Ayalon O, Goldrath T, Rosenthal G, Grossman M. Reduction of plastic carrier bag use. Waste Manag. 2009;29(7):2025-32. https://doi.org/ 10.1016/j.wasman.2009.02.016.

35. Martinho G, Balaia N, Pires A. The Portuguese plastic carrier bag tax: the effects on consumers' behavior. Waste Manag. $2017 ; 61: 3-12$. https://doi.org/10.1016/j.wasman.2017.01.023.

36. Thomas GO, Sautkina E, Poortinga W, Wolstenholme E, Whitmarsh L. The english plastic bag charge changed behavior and increased support for other charges to reduce plastic waste. Front Psychol. 2019;10:266. https://doi.org/10.3389/fpsyg.2019.00266.

37. Heidbreder LM, Bablok I, Drews S, Menzel C. Tackling the plastic problem: a review on perceptions, behaviors, and interventions. Sci Tot Environ. 2019;668:1077-93. https://doi.org/10.1016/j.scitotenv.2019.02.437.

38. Scientist Action and Advocacy Network (ScAAN). Effectiveness of plastic regulation around the world. 2019. https://plasticpollutioncoal itionresources.org/wp-content/uploads/2017/03/Effectiveness_of_plastic_regulation_around_the_world_4_pages.pdf.

Publisher's Note Springer Nature remains neutral with regard to jurisdictional claims in published maps and institutional affiliations. 